\title{
Regulations relating to mycotoxins in food
}

\author{
Perspectives in a global and European context
}

\author{
Hans P. van Egmond • Ronald C. Schothorst • \\ Marco A. Jonker
}

Received: 3 March 2007 /Revised: 12 April 2007 / Accepted: 20 April 2007 / Published online: 17 May 2007

(C) Springer-Verlag 2007

\begin{abstract}
Regulations relating to mycotoxins have been established in many countries to protect the consumer from the harmful effects of these compounds. Different factors play a role in the decision-making process of setting limits for mycotoxins. These include scientific factors, for example the availability of toxicological data and occurrence data, detailed knowledge about possibilities for sampling and analysis, and socio-economic issues. By the end of 2003, approximately 100 countries (covering approximately $85 \%$ of the world's inhabitants) had specific regulations or detailed guidelines for mycotoxins in food. The regulations were related to aflatoxins $\left(B_{1}, B_{2}, G_{1}\right.$ and $\left.G_{2}\right)$, aflatoxin $M_{1}$, trichothecenes (deoxynivalenol, diacetoxyscirpenol, T-2 toxin and HT-2 toxin), fumonisins ( $\mathrm{B}_{1}, \mathrm{~B}_{2}$, and $\left.\mathrm{B}_{3}\right)$, agaric acid, ergot alkaloids, ochratoxin $\mathrm{A}$, patulin, phomopsins, sterigmatocystin, and zearalenone. In Europe, and in particular in the EU, regulatory and scientific interest in mycotoxins has undergone a development in the last decade from autonomous national activity towards more EU-driven activity with a structural and network character. Harmonized EU limits now exist for 40 mycotoxin-food combinations. It is expected this number will grow in 2007 to approximately 50. The direct or indirect influence of European organizations and programs on the EU mycotoxin regulatory developments is significant. They include the European Food Safety Authority, the Scientific Cooperation on Questions relating to Food, the Rapid Alert System for Food and Feed, the creation of an EU Community Reference Laboratory for Mycotoxins and a mandate of the EC to the European Standardization Committee in methods for analysis for myco-
\end{abstract}

H. P. van Egmond $(\bowtie) \cdot$ R. C. Schothorst $\cdot$ M. A. Jonker Laboratory for Food and Residue Analysis,

National Institute for Public Health and the Environment,

P.O. Box 1, 3720 BA Bilthoven, The Netherlands

e-mail: hp.van.egmond@rivm.nl toxins in food. Large pan-European research and networking projects as "BioCop" and "MoniQA" are also important.

Keywords Mycotoxin - International - Regulation · Analysis · Food safety

\section{Introduction}

Mycotoxins are metabolites of fungi capable of having acute toxic, carcinogenic, mutagenic, teratogenic, immunotoxic, and oestrogenic effects in man and animals. Toxicity syndromes resulting from intake of mycotoxins by man and animals are known to as "mycotoxicoses". Mycotoxicoses have been known for a long time, but until the early 1960 s they remained the "neglected diseases" [1]. Since the discovery of the aflatoxins in 1960 and subsequent recognition that mycotoxins are of significant health concern to both humans and animals, regulations gradually developed for mycotoxins in food and feed. In the early days of mycotoxin regulations these measures focused mainly on the aflatoxins. They were established by industrialized countries, and limits often had an advisory or guideline character. Over the years, the number of countries with known specific mycotoxin regulations has increased from 33 in 1981 [2] to 56 in 1987 [3], 77 in 1995 [4], and 100 in 2003 [5]. Current regulations encompass 13 different mycotoxins or groups of mycotoxins, and specific limits have been established for many food and feed commodities and products.

Until the late 1990s setting of mycotoxin regulations was mostly a national affair. Gradually, several economic communities (e.g. EU (European Union), MERCOSUR (Mercado Cómun del Sur), Australia and New Zealand) harmonized their mycotoxin regulations, thereby overruling 
existing national regulations. Current regulations are increasingly based on scientific opinions of authoritative bodies, for example the FAO/WHO Joint Expert Committee on Food Additives of the United Nations (JECFA) and the European Food Safety Authority (EFSA). At the same time, requirements for adequate sampling and analytical methods put high demands on other professional organizations, for example AOAC International and the European Standardization Committee (CEN). In this article the factors affecting the constitution of mycotoxin regulations, and the role of different international organizations in the process of establishing and enforcing regulations, will be discussed. Some general observations are presented about the current situation on worldwide regulations for mycotoxins in food. The focus will then be directed on the European Union and the many European activities related to these regulatory developments.

\section{Factors affecting the promulgation of mycotoxin regulations}

A variety of factors may affect the promulgation of mycotoxin limits and regulations. These include:

- the availability of toxicological data of mycotoxins

- the availability of exposure data of mycotoxins

- knowledge of the distribution of mycotoxins concentrations within commodity or product lots

- the availability of analytical methods

- legislation in other countries with which trade contacts exist

- the need for sufficient food supply.

The first two factors provide the information necessary for hazard assessment and exposure assessment, respectively, the main bases of risk assessment. Risk assessment is the scientific evaluation of the probability of occurrence of known or potential adverse health effects resulting from human exposure to food-borne hazards. It is the primary scientific basis for promulgation of regulations. The third and fourth factors are important factors enabling practical enforcement of mycotoxin regulations, through adequate sampling and analysis procedures. The last two factors are merely socio-economic in nature but are equally important in the decision-making process to establish meaningful regulations and limits for mycotoxins in food and feed.

\section{Risk assessment}

Regulations are primarily based on known toxic effects. For the mycotoxins currently considered most significant (aflatoxins $\mathrm{B}_{1}, \mathrm{~B}_{2}, \mathrm{G}_{1}$ and $\mathrm{G}_{2}$; aflatoxin $\mathrm{M}_{1}$; ochratoxin $\mathrm{A}$; patulin; fumonisins $\mathrm{B}_{1}, \mathrm{~B}_{2}$ and $\mathrm{B}_{3}$; zearalenone; $\mathrm{T}-2$ and HT-2 toxins; and deoxynivalenol) the Joint Expert Com- mittee on Food Additives (JECFA - a scientific advisory body of the World Health Organization (WHO) and the Food and Agriculture Organization (FAO)) has evaluated their hazard in several sessions [6-12]. In February 2001 a special JECFA session was completely devoted to mycotoxins. Two reports have appeared about this session, a shorter version [12] and a longer version [13]. These reports provide good and detailed insight into the process of risk assessment of mycotoxins. The reports addressed several concerns about the mycotoxins considered-their properties and metabolism, toxicological studies, and final risk evaluation. With the mycotoxin evaluations the Committee discussed general considerations on sampling, analytical methods, associated intake issues, and control.

Risks associated with mycotoxins depend on both hazard and exposure. The hazard of mycotoxins to individuals is probably more or less the same all over the world (although other factors are, sometimes, also important, e.g. hepatitis B virus infection in relation to the hazard of aflatoxins). Exposure is not the same, because of different levels of contamination and dietary habits in the various parts of the world. Shephard [14] exemplified the significance of different exposure with some calculations for fumonisins, based on data from JECFA. JECFA established a group provisional maximum tolerable daily intake (PMTDI) for fumonisins $B_{1}, B_{2}$, and $B_{3}$ together of $2 \mu \mathrm{g} \mathrm{kg}^{-1}$ body weight per day [12]. This PMTDI is easily exceeded by individuals on a maize-based diet, when maize consumption is approximately $400 \mathrm{~g}$ per person per day, a situation found in some parts of Southern Africa. Shephard calculated that at a contamination level for fumonisins in maize of $2000 \mu \mathrm{g} \mathrm{kg}^{-1}$ (a level within the range of common regulatory limits) dietary exposure for a $60-\mathrm{kg}$ adult would be $13 \mu \mathrm{g} \mathrm{kg}^{-1}$ body weight per day, or $650 \%$ of the PMTDI. In the developed world maize intake is usually less than $10 \mathrm{~g}$ per person per day [15] and food contaminated at levels as high as $12 \mathrm{mg} \mathrm{kg}^{-1}$ can be consumed before dietary exposure exceeds the PMTDI set by JECFA.

On the basis of these data Fig. 1 has been constructed to show how consumption data may affect the setting of regulatory limits. Assuming a tolerable daily intake (TDI) for fumonisins of $120 \mu \mathrm{g}$ per person $\left(2 \mu \mathrm{g} \mathrm{kg}^{-1}\right.$ body weight, $60 \mathrm{~kg}$ ), Fig. 1 shows where the regulatory limit should be set, depending on consumption. The area under the TDI curve is the "safe area", in contrast with the area above the curve - the undesired area. As an example, in a country in which maize consumption is approx. $15 \mathrm{~g}$ per capita per day a legal limit of $8 \mathrm{mg} \mathrm{kg}^{-1}$ would suffice to prevent the TDI being exceeded. In another country where maize consumption is approx. $125 \mathrm{~g}$ per capita per day, however, a legal limit of $1 \mathrm{mg} \mathrm{kg}^{-1}$ would be required to give the same level of protection. In reality the spread of maize consumption throughout the world is even broader. 
Fig. 1 Effect of different daily maize consumption by populations worldwide on the setting of limits for fumonisins
Limit [mg FUM/kg maize]

20

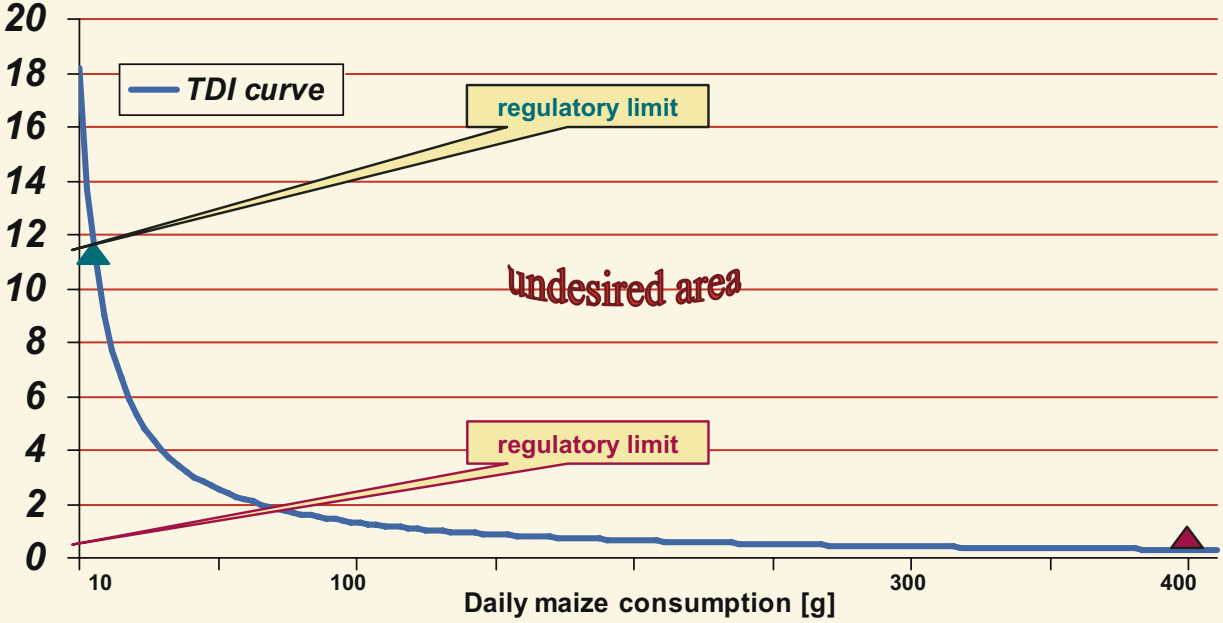

Note, however, that the example above is simplified. For example, it ignores other possible food sources which may contribute to fumonisins exposure. It may help, however, to realize that harmonisation of regulations per se does not necessarily lead to equal health protection. It also stresses the importance of reliable consumption data if meaningful mycotoxin regulations are to be developed.

Exposure assessment is an important aspect of risk assessment, and reliable data on the occurrence of mycotoxins in different commodities and data on food intake are needed. Quantitative evaluation of intake of mycotoxins is quite difficult. During its 56th meeting JECFA stressed the importance of using validated analytical methods and application of analytical quality assurance (see also the section on analysis) to ensure that the results of surveys provide a reliable assessment of intake [12]. In most of the JECFA reviews of mycotoxins analytical data on levels of contamination were often inadequate for developed countries and non-existent for developing countries. Because most mycotoxin contamination is heterogeneously distributed, adequate sampling is another important consideration for obtaining information on levels of contamination (see also the section on sampling). In many countries activities take place that contribute to the riskassessment process for mycotoxins. In the EU, for example, an important role is played by the European Food Safety Authority (EFSA). EFSA makes use, where possible, of exposure and consumption data, generated by the European SCOOP activities (see the section "The European dimension" for more details about EFSA and SCOOP).

\section{Sampling}

The distribution of the concentration of mycotoxins in products is an important factor to be considered when establishing regulatory sampling criteria. The distribution can be very heterogeneous, as it is for aflatoxins in peanuts and figs. The number of contaminated peanut kernels in a lot is usually very low but the level of contamination within a kernel can be very high. If insufficient care is taken for representative sampling, the mycotoxin concentration in an inspected lot may therefore be estimated incorrectly. Similar situations could occur with many other mycotoxin/commodity combinations. Adequate sampling is necessary to make justified management decisions about what to do with lots that may be contaminated with mycotoxins. Because of variability among sample test results, mycotoxin concentrations in lots cannot be determined with $100 \%$ certainty by taking samples from the lot.

Detailed studies on the variability associated with sampling, sample preparation and laboratory testing of feed and feed commodities have been conducted in the USA by Whitaker [16]. This resulted in a series of sampling plans for different mycotoxin-commodity combinations, outlined in Fig. 2 [17]. Whitaker developed so-called operating characteristic curves (OC curves) for each of these. An OC curve is a plot, representing a certain sampling plan, which shows the dependence of the probability of accepting a lot with a particular toxin concentration on the toxin concentration in the lot. OC curves show the risk of acceptance of lots that do not fulfil regulatory requirements (false negatives - buyer's risk) and, at the same time, the risk of unjustified rejection (false positives - seller's risk). It seems that sampling errors are usually (much) larger than samplepreparation errors and analytical errors; this results in much uncertainty about the true mycotoxin concentration in inspected lots. Increased sample sizes have the positive benefits of reducing both buyers' and sellers' risks associated with classifying lots above and below a specified 


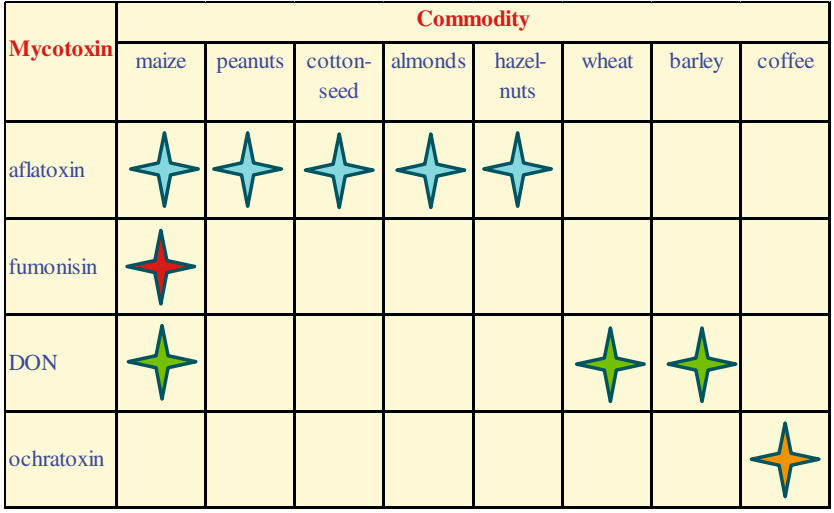

Fig. 2 Sampling plans for mycotoxins in different commodities, as developed by Whitaker [17]

tolerance, e.g. a regulatory limit. A change of accept-reject limits also has a marked effect on these risks. Regulatory authorities must consider these buyers' and sellers' risks (sometimes also called as consumers' and producers' risks) when establishing sampling criteria for products in which mycotoxins are heterogeneously distributed.

Several countries have gradually established detailed science-based sampling plans, which take into account the heterogeneous distribution of mycotoxins in agricultural commodities. Examples of official sampling plans for mycotoxins are those applied by the USA for aflatoxins in peanuts [18] and by the EU for several mycotoxins [19]. Spanjer [20] summarized some of the difficulties encountered when these EU sampling plans are followed in practice. This was illustrated by considering an EU sampling directive for import control on nuts packed in sacks - two food inspectors would need half a working day to sample only one container on just one ship. Spanjer indicated that in many other circumstances the situation is even more unmanageable - because the commodity is loaded in bulk or, just the opposite, when it consists of consumer or vacuum packages. The EU sampling directive seems to offer the possibility of alternatives as it states: "If it is not possible to carry out the method of sampling described above because of the unacceptable commercial consequences resulting from damage to the lot (because of packaging forms, means of transport, etc) an alternative method of sampling may be applied provided that it is as representative as possible and is fully described and documented". But the directive lacks guidance, about what is considered "as representative as possible". Spanjer recommended simplified sampling procedures, e.g. checking at import control only, to overcome some of the problems.

\section{Analysis}

Legislation calls for monitoring methods. Reliable analytical methods must be available to enable enforcement of the regulations in daily practice. In addition to reliability, simplicity is desired, as it will affect the amount of data generated and the practicality of the ultimate measures taken. The reliability of mycotoxin analysis data can be improved by use of interlaboratory-validated methods of analysis (e.g. the methods of AOAC International and methods standardized by CEN). These methods have been largely developed in response to planned regulations for mycotoxins or regulations that came into force. The requirements for these methods were dictated by the needs, i.e. they had to be suitable for the (planned) regulated mycotoxin-matrix combination(s). The limits of determination of the methods had to be demonstrated to be low enough for precise and accurate determination of the mycotoxins of interest at regulatory levels. Methods were also developed and validated for toxin-matrix combinations for which there were no regulations (yet), but for which the scientific community saw a need, e.g. for surveillance purposes. These developments eased the establishment of specific mycotoxin regulations.

AOAC currently has approximately 45 analytical methods for determination of mycotoxins [21]. All have undergone extensive testing in interlaboratory validation studies, and subsequent review by the AOAC's rigorous approval process. AOAC methods are referred to as official methods in mycotoxin legislation in a few dozen countries [5]. In Europe, CEN methods are becoming increasingly important. Ten mycotoxin methods have been standardized by the CEN, and this number will grow substantially in the years to come (see also the section "The European dimension"). Although CEN mycotoxin methods are not mandatory for official food control in the EU, all CEN mycotoxin methods can be used in the EU for official food-control purposes, because their performance characteristics fulfil the criteria, laid down in the EU regulation for sampling and analysis [19]. Figure 3 shows that worldwide official mycotoxin methods are still largely based on chromatographic procedures. Thin-layer chromatography, an established separation technique in mycotoxin methodology, is still of major importance in regulatory analysis.

The use of good, validated methods of analysis is no guarantee that reliable analytical results will be obtained in mycotoxin determination. Analytical quality assurance (AQA) is another prerequisite for adequate food-law enforcement. AQA includes, where possible, the use of (certified) reference materials (e.g. CRMs supplied by the European Commission's Joint Research Centre/Institute for Reference Materials and Measurements; JRC/IRMM, see http://www. irmm.jrc.be). CRMs currently available for mycotoxins, and those expected to become available in the near future, are listed in Table 1 [22]. Very important, especially in free trade areas, is how enforcement bodies handle the issue of measurement uncertainty. European legislation for mycotox- 


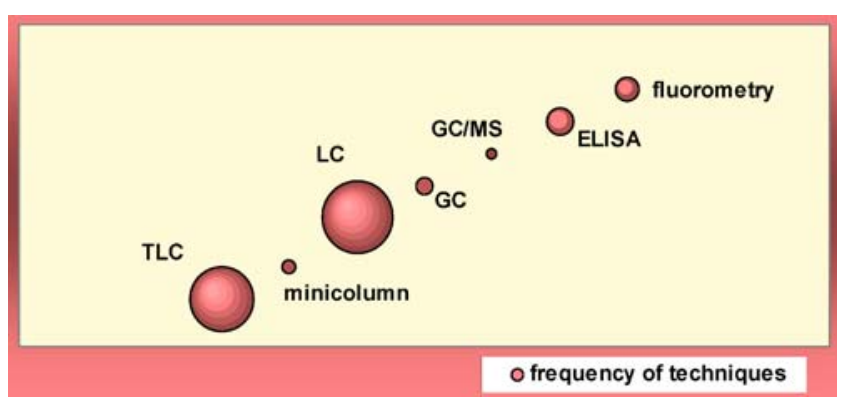

Fig. 3 Analytical techniques used for mycotoxin regulatory analysis. The size of the ball is proportional with the frequency of use of the technique (in 2004) [5]

ins now requires that "The analytical result must be reported as $x \pm U$, where $x$ is the analytical result and $U$ is the expanded measurement uncertainty" $[19,23]$, but detailed guidance how to estimate measurement uncertainty is not yet provided. The CEN has been mandated by the EC to prepare a new document on criteria for standardized methods to determine mycotoxins in the near future. This document will include discussion of measurement uncertainty (see also the section "The European dimension").

\section{Trade contacts and food supply}

Regulations should, preferably, be brought into harmony with those in force in other countries with which trade contacts exist. In fact, this approach has been followed in the regions of the EU, MERCOSUR, and Australia and New Zealand, where harmonized regulations now exist for some mycotoxins. Strict regulatory actions may lead countries to ban or limit the import of commodities; this can make it difficult for exporting countries to find or maintain markets for their products. Distortion of the market because of mycotoxin regulations in importing countries could lead to export of the less contaminated food and feed, leaving inferior food and feed for the local market. In a World Bank report [24] estimates were made on the relationship between aflatoxin $\mathrm{B}_{1}$ regulatory standards and trade flow. Studies for cereals and nuts predict significant losses for exporting countries (Africa) if stringent standards, such as those in force in the EU, were be adopted. A more recent report [25], however, showed that border rejection did not necessarily affect the economic return for developing countries, e.g. the African share of the EU market for dried fruit increased. Although border rejections were irritating to exporters, some producing countries increased their EU market share.

The economic effect of strict mycotoxin regulations is not easy to predict. Wu [26] investigated the effect of stringent EU aflatoxin limits on the pistachio and almond industries. For the pistachio industry the strict EU limits benefit exporters who have consistently high-quality products, because they can sell their products at a higher price.
Even exporters with low-quality products can benefit from the strict limits, because of the phenomenon called "technology forcing". They adopt technologies enabling better control of aflatoxins. This happened with the Iranian pistachio industry. The almond industry, in contrast has mainly losers. The US almond industry has suffered from the strict EU regulations, despite having a high-quality product. EU food industries also are suffering from the strict limits. The limits reduce supply. This causes prices to rise, only some of which can be passed on to the consumer. Wu recommended that EU policy makers should consider the economic impact of strict mycotoxin limits on their own food industries and citizens. Interestingly, this is already one of the objectives of the new EU project MoniQA (see also the section "The European dimension").

Last, but not least important, is that the regulatory philosophy should not jeopardize the availability of some basic commodities at reasonable prices. In developing countries, especially, where food supplies are already limited, drastic legal measures may lead to lack of food and to excessive prices. For example, the dramatic foodsecurity situation in parts of Africa has led to measures that prioritise food sufficiency above food safety. Mycotoxins are an important problem, as is apparent from occasional outbreaks of human mycotoxicoses, for example acute aflatoxicosis in Kenya in 2004 and 2005 [27], the role of aflatoxins in liver cancer, the stunted growth in children in western Africa [28], and fumonisins in oesophageal cancer in South Africa [14]. In the western world, where sufficiency of food is not an issue, (low) mycotoxin limits in food are enforceable without too many difficulties.

\section{Synopsis}

Weighing the various factors at the interface of science, food security, and regulations is not a trivial activity and

Table 1 BCR and IRMM (certified) reference materials developed for mycotoxins (February 2007) [22]

\begin{tabular}{lll}
\hline Certified reference material & Available & $\begin{array}{l}\text { (Re-) } \\
\text { development }\end{array}$ \\
\hline $\begin{array}{l}\text { Aflatoxin } \mathrm{M}_{1} \text { in milk powder } \\
\text { Aflatoxin } \mathrm{M}_{1} \text { calibrant }\end{array}$ & $\mathrm{x}$ & \\
Aflatoxins in peanut butter & $\mathrm{x}$ & $(\mathrm{x})$ \\
Aflatoxin $\mathrm{B}_{1}$ in peanut meal & $\mathrm{x}$ & \\
Aflatoxin $\mathrm{B}_{1}$ in feedstuff & $\mathrm{x}$ & $\mathrm{x}$ \\
Aflatoxins $\mathrm{B}_{1}, \mathrm{~B}_{2}, \mathrm{G}_{1}, \mathrm{G}_{2}$ calibrants & & \\
Ochratoxin A in wheat & $\mathrm{x}$ & $\mathrm{x}$ \\
Ochratoxin A calibrant & & \\
DON in maize and wheat & $\mathrm{x}$ & $\mathrm{x}$ \\
T-2 and HT-2 calibrants & & \\
Zearalenone in maize & $\mathrm{x}$ & \\
Zearalenone calibrant & $\mathrm{x}$ & \\
\hline
\end{tabular}


common sense is a major factor in reaching a decision. Public health officials are confronted with a complex problem-mycotoxins, particularly the carcinogenic mycotoxins, should be excluded from food as much as possible. Because the substances are present in foods as natural contaminants, however, human exposure cannot be completely prevented, and exposure of the population to some level of the mycotoxins has to be tolerated. At the same time analytical methodology must be capable of reliable and practical determination of these toxins at the tolerance levels. Despite the dilemmas, in recent decades mycotoxin regulations have been established in many countries and newer regulations are still being drafted. In the European Union, in particular, many developments are occurring in mycotoxin regulation which are scientifically underpinned and supported by a variety of European organisations and activities.

\section{The international mycotoxin regulatory situation}

\section{Worldwide mycotoxin regulations}

Several times in recent decades (1981, 1987, 1995, 2003) international inquiries were held and published about regulations for mycotoxins in food and feed [2-5]. The most recent enquiry in 2003 was conducted by the National Institute for Public Health and the Environment, under contract to the FAO, among the Agricultural Services of Dutch Embassies around the world, with the request to gather up-to-date information from local authorities on the situation regarding mycotoxin regulations in as many countries of the world as possible. Where this procedure did not lead to the desired information, personal contacts were used. By the end of 2003 data had been received from 89 countries. Together with information gathered in previous enquiries, detailed information became available about the existence or absence of specific mycotoxin limits and regulations in food and feed in 119 countries. All the data received were sorted by country and by economic community (ASEAN, Australia and New Zealand, EU, MERCOSUR). Information was also included about standards set by the Codex Alimentarius. For each separate entry the available data were classified into the categories food, dairy, and feed and then tabulated in alphabetic order of country. The results of the enquiry were published in detail by the FAO in Food and Nutrition Paper in English, French, Spanish, and Chinese [5].

At least 99 countries had mycotoxin regulations for food and/or feed in 2003, an increase of approximately $30 \%$ compared with 1995 . Whereas in $199523 \%$ of the world's inhabitants lived in a region where no known mycotoxin regulations were in force, this percentage has decreased to $13 \%$ in 2003 , with the benefit of slight increases in coverage in Latin America and Europe and more significant increases in Africa, Asia, and Oceania. All countries with mycotoxin regulations in 2003 had regulatory limits for at least aflatoxin $B_{1}$ or the sum of aflatoxins $B_{1}, B_{2}, G_{1}$, and $\mathrm{G}_{2}$ in food and/or feed, a situation that was also true in 1995. Ranges and major limits for total aflatoxins in food in 2003 are depicted in Fig. 4 for the different regions of the world. Specific regulations also exist for several other mycotoxins (aflatoxin $\mathrm{M}_{1}$; the trichothecenes deoxynivalenol, diacetoxyscirpenol, T-2 toxin and HT-2 toxin; the fumonisins $\mathrm{B}_{1}, \mathrm{~B}_{2}$, and $\mathrm{B}_{3}$; agaric acid; the ergot alkaloids; ochratoxin $\mathrm{A}$; patulin; phomopsins; sterigmatocystin, and zearalenone). Most of the limits are set for human foods. Typically higher regulatory levels are used for animal feed. Information about all the regulatory limits in force around the world for various commodities, with information about their legal basis, the responsible authorities, the methods used for sampling and analysis, and a series of graphical presentations of the regulatory situations, are published in detail in FAO Food and Nutrition Paper 81 [5]. The number of countries regulating mycotoxins has increased significantly over the years. If the situations in 1995 and 2003 are compared it seems that in 2003 more mycotoxins were regulated in more commodities and products and that tolerance limits usually remained the same or tended to decrease. Regulations have become more diverse and detailed with newer requirements with regard to official procedures for sampling and analytical methodology.

\section{The European dimension}

In Europe, and in particular in the EU, regulatory and scientific interest in mycotoxins has undergone a development in the last decade from national activities and approaches towards more EU-driven activities with a structural and network character. This can be seen not only in the

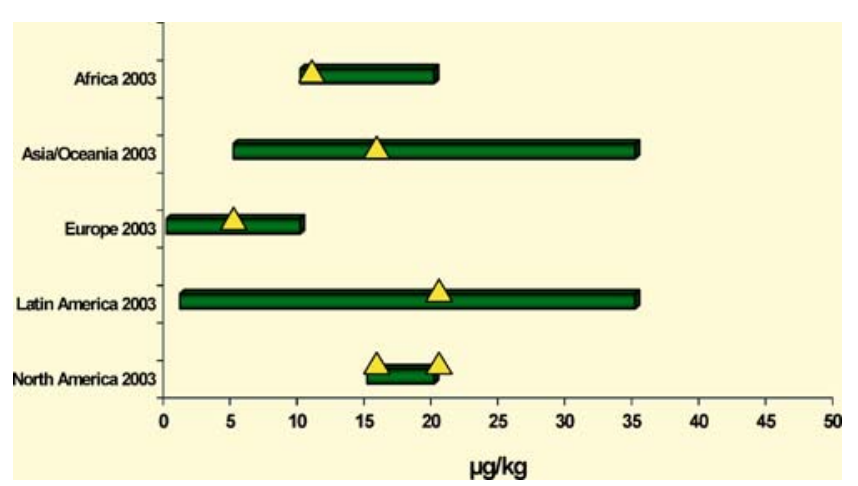

Fig. 4 Ranges (bars) and major limits (triangles) for total aflatoxins in food [5] 
harmonization of (stringent) legal limits for mycotoxins, but also in the increased significance that European programs and organizations play, in direct or indirect support of these regulatory developments in the Community.

Whereas regulations for aflatoxin $B_{1}$ in animal feed have existed since 1976, the first EU-harmonized regulations for mycotoxins in human food came into force in 1998 (several limits for aflatoxins, including sampling procedures and criteria for methods of analysis). They have gradually expanded to a variety of mycotoxins in different foodstuffs, including baby and children foods. At the time of writing limits have been set for approximately 40 toxin-food commodity combinations [29] and limits for a further ten toxin-commodity combinations are coming into force for several Fusarium toxins during 2007. New limits will probably also be established in the years to come for ergot alkaloids in foods, and some limits may be revised for aflatoxins, depending on EFSA scientific opinions. The EFSA is an independent body of the European Commission, established in 2002, and charged, among other tasks, with the development of risk assessments on issues of concern in the food and feed supply. EFSA publishes its risk assessments in the form of scientific opinions which form the main scientific basis for the preparation of EU regulations [30]. Opinions about risks of mycotoxins in food and feed are developed in EFSA's panel on contaminants in the food chain. As an example, this panel has recently (March 2007; $h t t p: / / w w w . e f s a . e u r o p a . e u)$ published an opinion on the potential increase in the risk to consumer health of a possible increase in current maximum levels for aflatoxins in almonds, hazelnuts, pistachios, and derived products. The panel concluded that changing the maximum levels for total aflatoxins in almonds, hazelnuts, and pistachios from 4 to 8 or $10 \mu \mathrm{g} \mathrm{kg}^{-1}$ would have minor effects on estimates of dietary exposure and cancer risks. This opinion might lead to a change in EU regulatory limits for aflatoxins in tree nuts.

Another important EU activity is SCOOP (Scientific Cooperation on Questions relating to Food), funded by the European Commission, and targeted to make the best estimates of intake of contaminants by EU inhabitants. In the 1990s these activities resulted in a report assessing exposure to aflatoxins [31]. SCOOP reports were later published for several other mycotoxins including ochratoxin A [32], patulin [33], and several Fusarium toxins (trichothecenes, fumonisins, and zearalenone) [34]. The objectives of this SCOOP activity is to provide the scientific basis for evaluation and management of risk to public health arising from dietary exposure to mycotoxins, taking into account recently available data on occurrence and consumption. Special emphasis is placed on evaluation of dietary intake of mycotoxins in each of the EU member states and in high-risk sub-groups of the population. Data provided by participants in the SCOOP exercises were collected, harmonised, and reported with the following objectives:

- to provide a description, harmonised at European level, of the status of mycotoxin contamination of foodstuffs in each participating member state;

- to group available information on each raw material and/or food product;

- to evaluate the best estimates of the mycotoxin dietary intake from food, both for each participating member state and at European level; and

- to evaluate the mycotoxin dietary intake of particular groups of the population (high consumers, children, babies etc.).

Care had to be taken with interpretation of the dietary intake results, however, because for a limited number of positive samples mean occurrence levels are strongly affected by the limit of detection of the analytical methods used and this can easily contribute to overestimation of calculated total dietary intake. One major outcome of the recent SCOOP activity on Fusarium toxins was that consumption data for specific population groups (for example children) should be collected, to assess more accurately the exposure of the European population. Another was that a common approach to assessing dietary intake in European countries should be elaborated. Figure 5 shows estimated dietary intake of deoxynivalenol for different population groups in several EU countries [35], compared with the tolerable dietary intake (TDI) of deoxynivalenol, as established by the JECFA [13]. Figure 5 makes clear that in some countries the TDI is exceeded for some or all intake groups of the population.

SCOOP exercises make it clear that mycotoxins are among the chemical contaminants in food to which EU inhabitants may be exposed. Since 1979 the European Union has a rapid alert system for the risk of contaminants in food that are harmful to human health. The introduction of the General Food Law in 2002 [36] was an important step in the evolution of the rapid alert system for food and feed (RASFF) as it exists nowadays. The system involves rapid information exchange between the competent authorities of the member states (including EFTA/EEA countries), the European Commission itself, and the EFSA. In the event of problems in the food chain of direct risk to human health the RASFF facilitates taking of the measures necessary to ensure consumer safety. Different kinds of notification-news notification, information notification, and alert notification - can be arranged, depending on the extent of risk and the need for direct action. News notification is related to information about food or feed safety. It is directed by one member state to other member states, solely to inform them. Information notification describes an identified risk of food or feed at the outer 


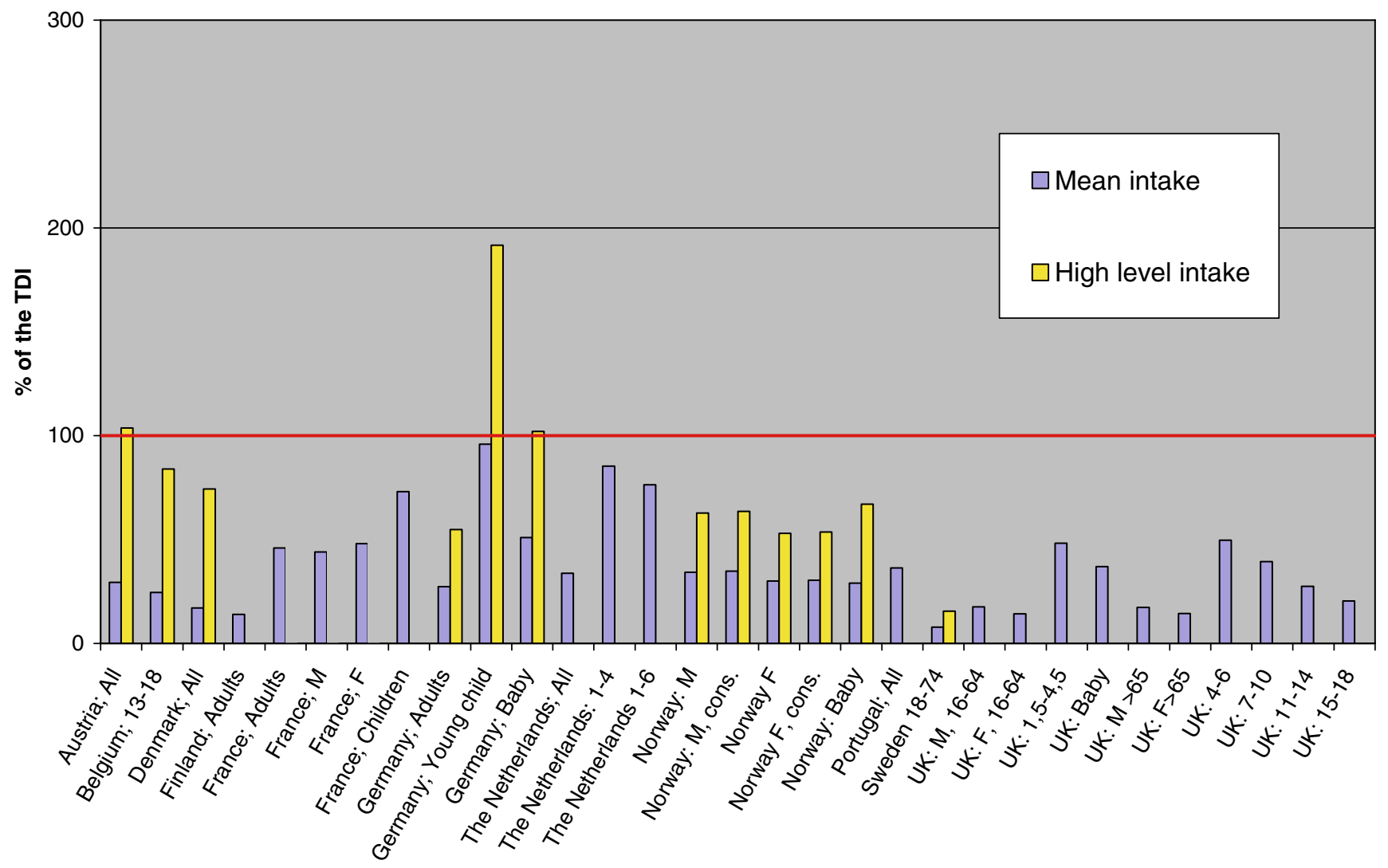

Fig. 5 Estimated dietary intake of deoxynivalenol by different population groups in several EU countries, and comparison with the JECFA tolerable daily intake [35]

border of the EU, but requires no immediate action of other member states, although the problem also might exist for their countries. An alert notification relates to products that are on the market already. It is immediately transmitted by the Commission to other members of the network and leads to withdrawal of the risky products from the market.

In 2005 the RASFF received a total of 2254 information notifications [37] of which 906 related to risks to human health of mycotoxins. This means that a very high percentage had to be ascribed to an identified problem with mycotoxins, as illustrated in Fig. 6. It can, moreover, be concluded from the figure that problems with mycotoxins were much greater than those of other menaces. Almost $90 \%$ of these mycotoxin notifications were related to human health risks from aflatoxins in nuts (pistachio nuts, peanuts, hazel nuts, almonds) and nut products (peanut butter) which were imported into the EU in 2005. Other notifications concerned risks of aflatoxins in fruit and vegetables (dried figs and derived products, and melon), and herbs and spices (chilli, paprika, curry, and nutmeg). Notifications were also sent for ochratoxin A in the same products as aflatoxins and, moreover, in coffee and coffee products and in cereals and cereal products. Finally, a much smaller number of these notifications were sent to the partners in the relevant network in relation to risks of fumonisins in cereal products and of patulin in baby food and fruit juices.

RASFF notifications provide useful data for the development of new EU measures as new Commission regulations and safeguard measures such as the special conditions for import of pistachio nuts from Iran [38]. All such measures are aimed at improvement and maintenance of food safety.

Since July 2006, the European Commission's Joint Research Centre/Institute for Reference Materials and Measurements (Geel, Belgium) has fulfilled the role of EU Community Reference Laboratory (CRL) for mycotoxins.

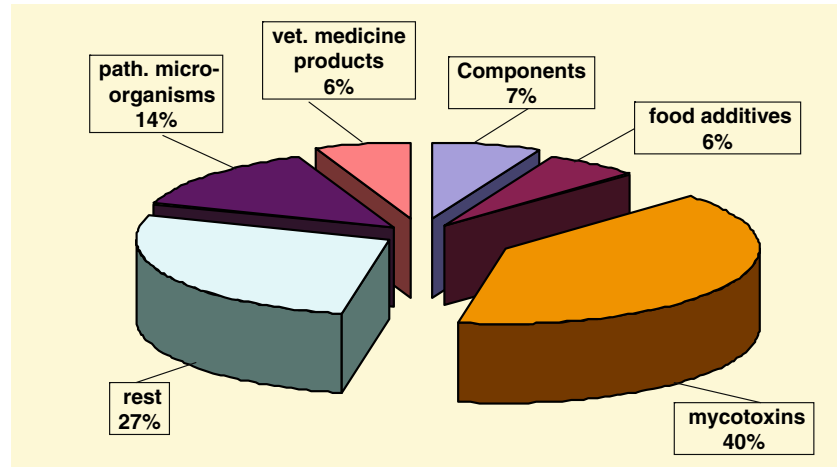

Fig. 6 Information notifications distributed to the relevant network members of the EU rapid alert system for food and feed in 2005 [37] 
The tasks, duties, and requirements of CRLs in relation to food, feed, and animal health have been published [39]. Figure 7 gives an impression of the main CRL tasks and its position in the EU. Among other duties the CRL for mycotoxins has been created to take initiatives and to coordinate activities related to the development, improvement, and application of sample preparation and methods of analysis for official control of maximum levels for mycotoxins in food and feed. Among the tasks mentioned is the function "to provide technical assistance to the Commission and, upon its request, to participate in international fora relating to the area of competence, concerning in particular the standardization of analytical methods and their implementation". So, it is evident that the link with the European Standardization Committee (CEN) will be important.

The position of the CEN with regard to mycotoxin regulations will also be strengthened as a consequence of the European Commission's “Mandate for standardization addressed to CEN in the field of methods of analysis for mycotoxins in food" [40]. The new mandate falls within the framework of regulation EC no. 882/2004 [39]. This regulation stipulates that methods for sampling and analysis used in the context of official control shall comply with relevant Community rules or, if no such rules exist, with internationally recognized rules or protocols, for example those that the CEN has accepted. The view of the European Commission on CEN standards is clear: "The establishment of standardized methods of analysis is of utmost importance to guarantee a uniform application and control of the European legislation in all Members States. Standardized methods of analysis are an indispensable element in guaranteeing a high level of food safety".

In the text of the mandate a statement is made that elaboration of the standards should be undertaken in cooperation with the broadest possible range of interested groups.

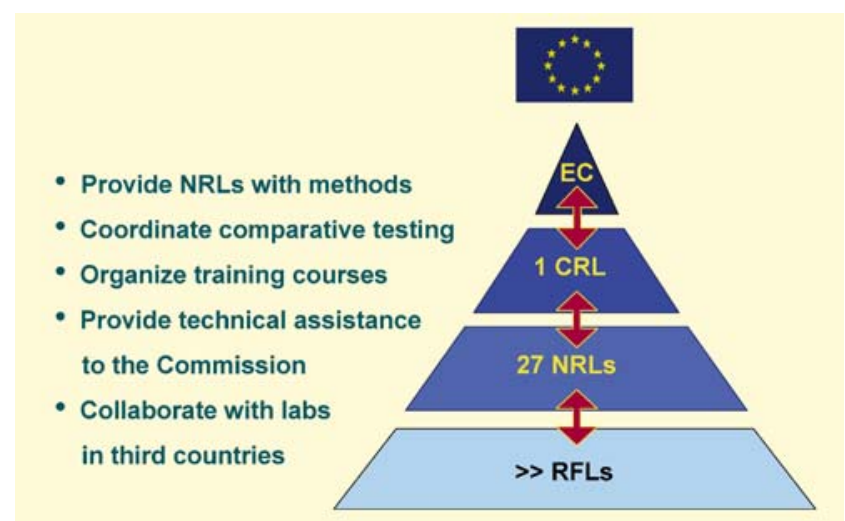

Fig. 7 Tasks and positioning of the EU Community Reference Laboratory for mycotoxins. EC, European Commission; $C R L$, Community Reference Laboratory; $N R L$, National Reference Laboratory; RFL, Routine Field Laboratory
Twelve such (mainly European) organizations are specifically mentioned in the mandate, which shows the importance that the European Commission attaches to a broad support for the standardized methods. In the annex of the mandate the methods of analysis are specifically mentioned. These relate to patulin, deoxynivalenol, zearalenone, aflatoxin $\mathrm{B}_{1}$, ochratoxin $\mathrm{A}$, and fumonisins $\mathrm{B}_{1}$ and $\mathrm{B}_{2}$ in a variety of foodstuffs. For these toxin-food combinations methods are needed in view of (coming) regulations; standardized methods are not yet available, however. One of a list of tasks to be undertaken is the preparation of a review of updated and extended performance criteria for methods of analysis of mycotoxins. The objective is to produce an updated and extended version of the current CEN criteria document [41], which has been the basis for stipulating performance criteria for mycotoxin methods in current EU legislation. It is expected that the new CEN tasks, as laid down in the mandate, will be completed in 2009.

In addition to the guiding or supporting role of the European organisations and structural activities described above in establishment of mycotoxin regulations in the EU, results from several EC-funded research projects may also affect EU mycotoxin regulations. Without intentionally ignoring other relevant EC projects, examples of projects with significant potential impact include "BioCop" and "MoniQA". These two projects are funded in the EC's 6th Framework Programme.

"BioCop" (http://www.biocop.org) is an integrated project (IP) with more than 30 partners focussing on "new technologies to screen multiple chemical contaminants in foods". This pan-European project runs from 2005 until 2010. BioCop methods are based not on chromatography but on new biotechnology, for example transcriptomics, proteomics, and biosensors. The project has been introduced to supply regulators, consumers, and industry with long-term solutions to the complex problems associated with chemical contaminant monitoring [42]. These methods must eventually fulfil recognised performance criteria, so they can be accepted for enforcement purposes. One of the work packages of Biocop is to deal with mycotoxins, more specifically with the development of new methods, including use of transcriptomics (identification of chemical residues by genomic fingerprints) and sensors (both low-cost (electrochemical) portable devices and surface plasmon resonance (SPR) sensors) for analysis of a selection of trichothecenes of European interest (deoxynivalenol, nivalenol, and T-2 and HT-2 toxins). If successful in the first phase, the methods will be validated in interlaboratory tests and standardized by the CEN working group Biotoxins, possibly in the period after the project has been finalized. Because mycotoxin methods permitted by EU legislation are based on performance criteria, the potential of BioCop-developed methods for regulatory use is significant. 
"MoniQA" (http://www.moniqa.org) is a network of excellence (NoE), at the time of writing just started to run in the period 2007-2011. MoniQA has more than 60 partners. Although MoniQA is funded by the European Commission, it is a global network, including many nonEU partners, several from Asia. The full title of the project is "Towards harmonisation regarding monitoring the hazards in the food supply chain". In MoniQA the core consortium seeks to establish mechanisms for coordinating and finally merging research activities, personnel, and infrastructure [43]. MoniQA is directed toward multidisciplinary themes, named "clusters". One of the main clusters is "mycotoxins". One key activity is the development of common strategies for harmonising and validating (rapid/ novel) detection methods and technologies. This could possibly include methods such as those developed in BioCop. A specific work package of MoniQA will evaluate the economic effect of implementation of the analytical methods required by the new regulations in the field of food quality and safety (e.g. effectiveness, efficiency, and consistency), and to compare the effect of different options in qualitative, quantitative, and monetary terms. Riskbenefit analysis is obviously receiving more attention.

With the funding of BioCop and MoniQA the European Commission has not ceased its interest in advancing the development and standardization of analytical methods and sampling methods for contaminants, including mycotoxins. In the newly launched 7th Framework Programme (ranging from 2007 to 2013) large collaborative projects are foreseen in which (rapid) methods for mycotoxins, sampling, and standardization issues will receive attention.

\section{Conclusions}

By the end of 2003 approximately 100 countries in the world had specific regulations in food and feed. The number of countries regulating mycotoxins has significantly increased over the years. Comparison of the situations in 1995 and 2003 reveals that in 2003 more mycotoxins were regulated in more commodities and products and that tolerance limits generally remained the same or tended to decrease. Regulations have become more diverse and detailed with newer requirements with regard to official sampling procedures and analytical methods. Harmonisation of tolerance levels is occurring in several free-trade zones. In the EU, especially, the number of harmonized regulations for mycotoxins in food has rapidly grown, and will grow further in the years to come. Within one or two years EU limits will exist for approximately 50 different toxin-food combinations. These developments are scientifically underpinned, supported, and flanked by the complementary activities of a variety of European organizations or programmes (e.g. EFSA, SCOOP, RASFF, CRL, and CEN). Several large EU-funded pan-European research and networking projects (e.g. BioCop, MoniQA) also have an effect. It is, therefore, expected that in the future the scientific basis and transparency of mycotoxin regulations and standardisation and harmonisation of the corresponding (bio)analytical methodology will benefit from these developments.

Acknowledgement The authors wish to thank the Food and Agriculture Organization of the United Nations for permission to make use of material published in 2004 in FAO Food and Nutrition Paper 81: "Worldwide regulations for mycotoxins in food and feed in 2003". Professor T.B. Whitaker (North Carolina State University, USA) is greatly acknowledged for permission to reproduce Fig. 2. Figure 5 was reprinted from Toxicology Letters 153, Schothorst RC and Van Egmond HP. Report from SCOOP task 3.2.10 "Collection of occurrence data of Fusarium toxins in food and assessment of dietary intake by the population of EU member states" Subtask: trichothecenes, 133-143. Copyright (2004), with permission from Elsevier [35].

\section{References}

1. Forgacs J, Carll WT (1962) Adv Vet Sci 7:273-282

2. Schuller PL, van Egmond HP, Stoloff L (1983) Limits and regulations on mycotoxins. In: Naguib K, Naguib MM, Park DL, Pohland AE (eds) Proc Int Symp on Mycotoxins, 6-8 September 1981, Cairo, Egypt, pp 111-129

3. Van Egmond HP (1989) Food Addit Contam 6:139-188

4. Food and Agriculture Organization (1997) Worldwide regulations for mycotoxins 1995. A compendium. FAO Food and Nutrition Paper 64. Food and Agriculture Organization of the United Nations, Rome, Italy

5. Food and Agriculture Organization (2004) Worldwide regulations for mycotoxins in food and feed in 2003. FAO Food and Nutrition Paper 81. Food and Agriculture Organization of the United Nations, Rome, Italy

6. World Health Organization (1990) Toxicological evaluation of certain food additives and contaminants. Chapter Patulin. The 35th meeting of the Joint FAO/WHO Expert Committee on Food Additives, WHO Geneva, WHO Food Additives Series 26:143-165

7. World Health Organization (1991) Toxicological evaluation of certain food additives and contaminants. Chapter Ochratoxin A. The 37th meeting of the Joint FAO/WHO Expert Committee on Food Additives, WHO Geneva, WHO Food Additives Series 28:365-417

8. World Health Organization (1995) Evaluation of certain food additives and contaminants: forty-forth report of the Joint FAO/ WHO Expert Committee on Food Additives. Ochratoxin A and Patulin. WHO Technical Report Series 859:35-38

9. World Health Organization (1996) Toxicological evaluation of certain food additives and contaminants. Chapters Ochratoxin A and Patulin. The 44th meeting of the Joint FAO/WHO Expert Committee on Food Additives, WHO Geneva, WHO Food Additives Series 35:363-402

10. World Health Organization (1999) Evaluation of certain food additives and contaminants. Aflatoxins. Forty-ninth report of the Joint FAO/WHO Expert Committee on Food Additives, WHO Geneva, WHO Technical Report Series 884:69-77

11. World Health Organization (2000) Evaluation of certain food additives and contaminants. Zearalenone. Fifty-third report of the 
Joint FAO/WHO Expert Committee on Food Additives, WHO Geneva, WHO Technical Report Series 896:93-96

12. World Health Organization (2002) Evaluation of certain mycotoxins in food. Fifty-sixth report of the Joint FAO/WHO Expert Committee on Food Additives, WHO Technical Report Series 906, World Health Organization, Geneva, Switzerland, p 70

13. Food and Agriculture Organization (2001) Safety Evaluation of Certain Mycotoxins in Food. Prepared by the Fifty-sixth meeting of the Joint FAO/WHO Expert Committee on Food Additives (JECFA). FAO Food and Nutrition Paper 74, Food and Agriculture Organization of the United Nations, Rome, Italy, p 705

14. Shephard GS (2004) Mycotoxins worldwide: current issues in Africa. In: Barug D, Van Egmond HP, López Garciá R, Van Osenbruggen WA, Visconti A (eds) Meeting the mycotoxin menace. Wageningen Academic Publishers, Wageningen, The Netherlands, pp 81-88

15. Shephard GS, Leggott NL, Stockenström S, Somdyala NIM, Marasas WFO (2002) S African J Sci 98:393-396

16. Whitaker TB (2006) Food Addit Contam 23:50-61

17. Whitaker TB (2007) Personal communication

18. Food and Drug Administration (2002) Food and Drug Administration Investigative Operations Manual http://www.fda.gov/ora/ inspect_ref/iom/Contents/ch4_TOC.html

19. Commission of the European Communities (2006) Commission Regulation (EC) No. 401/2006 of 23 February 2006 laying down the methods of sampling and analysis for the official control of the levels of mycotoxins in foodstuffs. Official Journal of the European Union L70:12-34

20. Spanjer M (2006) Theory and criteria for practical sampling. Abstracts of lectures and posters, The World Mycotoxin Forum, The Fourth Conference, Cincinnati, USA, November 6-8, 2006, p 55

21. AOAC International (2005) Official Methods of Analysis of AOAC International, 18th edn. AOAC International, Gaithersburg, USA

22. Emons H (2006) Use of certified reference materials to achieve reliable analytical results. Abstracts of lectures and posters, The World Mycotoxin Forum, The Fourth Conference, Cincinnati, USA, November 6-8, 2006, p 63

23. Stroka J, Van Egmond HP (2006) How to deal with measurement uncertainty in routine mycotoxin determination. In: Barug D, Bhatnagar D, Van Egmond HP, Van der Kamp JW, Van Osenbruggen WA, Visconti A (eds) The mycotoxin factbook. Food and feed topics. Wageningen Academic Publishers, Wageningen, The Netherlands, pp 295-310

24. Wilson J, Otsuki T (2001) Global trade and food safety: Winners and losers in a fragmented system. World Bank Working paper 2689, Washington DC, USA

25. World Bank (2005) Food Safety and Agricultural Health Standards. Challenges and Opportunities for Developing Country Exports. Report No. 31207 of the World Bank, Washington DC, USA

26. Wu F (2006) A tale of two commodities: how EU mycotoxin regulations have hurt, or helped, food industries. Abstracts of lectures and posters, The World Mycotoxin Forum, The Fourth Conference, Cincinnati, USA, November 6-8, 2006, p 30

27. Lewis L, Onsongo M, Njapau H, Schurz-Rogers H, Luber G, Kieszak S, Nyamongo J, Backer L, Dahiye AM, Misore A, DeCock K, Rubin C (2005) Environ Health Perspect 113:1763-1767

28. Gong YY, Cardwell K, Hounsa A, Egal S, Turner PC, Hall AJ, Wild CP (2002) Br Med J 325:20-21
29. Commission of the European Communities (2006) Commission Regulation (EC) No 1881/2006 of 19 December 2006 setting maximum levels for certain contaminants in foodstuffs. Official Journal of the European Union L364, pp 5-24

30. Anonymous (2006) Transparency in risk assessment carried out by EFSA: guidance document on procedural aspects. Request No EFSA-Q-2005-050. Endorsed on 11 April 2006 by the Scientific Committee. The EFSA Journal 353:1-16

31. European Commission (1997) Reports on tasks for scientific cooperation. Report of experts participating in Task 3.2.1. Risk assessment of aflatoxins. Report EUR 17526 EN, DirectorateGeneral for Industry, Office for Official Publications of the European Communities, Luxembourg

32. Miraglia M, Brera C (2002) Assessment of dietary intake of ochratoxin A by the population of EU Member States, January 2002, http://europa.eu.int/comm/food/fs/scoop/index_en.html

33. Majerus P, Kapp K (2002) Assessment of dietary intake of patulin by the population of EU Member States, March 2002, http:// europa.eu.int/comm/food/fs/scoop/index_en.html

34. Gareis M, Schothorst RC, Vidnes A, Bergsten C, Paulsen B, Brera C, Miraglia M (2003) SCOOP task 3.2.10. Collection of Occurrence Data of Fusarium Toxins in Food and Assessment of Dietary Intake by the Population of EU Member States, http:// europa.eu.int/comm/food/fs/scoop/task3210.pdf

35. Schothorst RC, Van Egmond HP (2004) Toxicol Lett 153:133-143

36. The European Parliament and the Council of the European Communities (2002) Regulation (EC) no 178/2002 of the European Parliament and of the Council of 28 January 2002 laying down the general principles and requirements of food law, establishing the European Food Safety Authority and laying down procedures in matters of food safety. Official Journal of the European Communities L31, pp 1-24

37. European Commission (2006) The Rapid Alert System for Food and Feed (RASFF) Annual Report 2005. Health and Consumer Protection Directorate-General, Office for Official Publications of the European Communities, Luxembourg

38. Commission of the European Communities (2005) Commission Decision of 26 January 2005 imposing special conditions on the import of pistachios and certain products derived from pistachios originating in, or consigned from Iran (notified under document number C(2005) 117) (2005/85/EC). Official Journal of the European Union L30, pp 12-18

39. Commission of the European Communities (2006) Commission Regulation (EC) No 776/2006 of 23 May 2006 amending Annex VII to Regulation (EC) No 882/2004 of the European Parliament and of the Council as regards Community reference laboratories. Official Journal of the European Union L136, pp 3-8

40. European Commission (2006) Mandate for standardization addressed to CEN in the field of methods of analysis for mycotoxins in food. Document M383/EN Health \& Consumer Protection Directorate-general. Directorate D-Food Safety: production and distribution chain. D3- Chemicals, contaminants and pesticides, Brussels, 7 February 2006

41. European Standardization Committee (CEN) (1999) Food Analysis-Biotoxins. Criteria of Analytical Methods of Mycotoxins. CEN Report CR 13505, Brussels, Belgium

42. Elliott C (2006) New Food 2:61-63

43. Van der Kamp JW, Poms RE (2006) The way to harmonize and validate analytical methods for mycotoxins. Abstracts of lectures and posters, The World Mycotoxin Forum, The Fourth Conference, Cincinnati, USA, November 6-8, 2006, p 59 